\title{
AN ALTERNATIVE PROOF OF A THEOREM OF BECKENBACH ${ }^{1}$
}

\section{EDGAR REICH}

Beckenbach [1] has shown that the following analogue of Schwarz's lemma holds:

THEOREM. If $f(z)$ is regular for $|z|<1$, and

$$
I(\rho, \theta)=\int_{0}^{\rho}\left|f\left(r e^{i \theta}\right)\right| d r \leqq 1, \quad 0 \leqq \rho<1,0 \leqq \theta<2 \pi,
$$

then $I(\rho, \theta) \leqq \rho$. Equality for any $\left(\rho_{0}, \theta_{0}\right)$, with $\rho_{0}>0$, implies $f(z)=e^{i \alpha \text {, }}$ $\alpha$ real.

We shall derive this theorem by using a device employed by Landau [2] for proving a theorem of Hardy.

By a change of variable of integration, (1) becomes

$$
I(\rho, \theta)=\rho \int_{0}^{1}\left|f\left(\rho t e^{i \theta}\right)\right| d t \leqq 1, \quad 0 \leqq \rho<1,0 \leqq \theta<2 \pi .
$$

Consider the function

$$
\begin{aligned}
F(\rho, \theta, z)=z \int_{0}^{1} f\left(z t e^{i \theta}\right) & \exp \left[-i \arg f\left(\rho t e^{i \theta}\right)\right] d t, \\
0 & \leqq \rho<1,0 \leqq \theta<2 \pi, 0 \leqq|z|<1 .
\end{aligned}
$$

For every fixed $\rho$ and $\theta, 0 \leqq \rho<1,0 \leqq \theta<2 \pi, F$ is an analytic function of $z$ for $|z|<1$, vanishing for $z=0$. Let $\sigma=\theta+\arg z$. Then

$$
|F(\rho, \theta, z)| \leqq|z| \int_{0}^{1}\left|f\left(z t e^{i \theta}\right)\right| d t=|z| \int_{0}^{1}\left|f\left(|z| t e^{i \sigma}\right)\right| d t \leqq 1
$$

by (2). Schwarz's lemma now implies that

$$
|F(\rho, \theta, z)| \leqq|z| \text {. }
$$

In particular, for $z=\rho$, we have

$$
|F(\rho, \theta, \rho)|=F(\rho, \theta, \rho)=I(\rho, \theta) \leqq \rho,
$$

Received by the editors October 8, 1953 and, in revised form, January 18, 1954.

1 The author wishes to thank Professor Beckenbach for suggesting the desirability of finding a purely complex-variable proof of this result which had previously been derived only by subharmonic function methods [1]. 
as was to be shown. The discussion for the case of equality in the conclusion of the theorem is straightforward.

More generally, by using a stronger form of Schwarz's lemma one can show that if in the hypothesis of the theorem one adds the statement that $f(z)$ has a zero of order $n$ at the origin, then one can actually conclude that $I(\rho, \theta) \leqq \rho^{n}$.

\section{REFERENCES}

1. E. F. Beckenbach, $A$ relative of the lemma of Schwarz, Bull. Amer. Math. Soc. vol. 44 (1938) pp. 698-707.

2. E. Landau, Neuer Beweis eines Hardyschen Satzes, Arch. d. Math. u. Physik (3) vol. 25 (1916) pp. 173-178.

The Rand Corporation and

University of California, Los Angeles 